REVIEW ARTICLE

\title{
Evolutionary strategies and adaptations for survival between mosquito-parasitic microsporidia and their intermediate copepod hosts: a comparative examination of Amblyospora connecticus and Hyalinocysta chapmani (Microsporidia: Amblyosporidae)
}

\author{
Theodore G. Andreadis
}

The Connecticut Agricultural Experiment Station, 123 Huntington Street, P.O. Box 1106, New Haven, Connecticut 06504, USA

Key words: Microsporidia, Amblyospora connecticus, Hyalinocysta chapmani, mosquito, Ochlerotatus cantator, Culiseta melanura, copepod, Acanthocyclops vernalis, Orthocyclops modestus

\begin{abstract}
The epizootiology, transmission dynamics, and survival strategies employed by two mosquito-parasitic microsporidia that utilize copepods as intermediate hosts are examined in relation to the biological attributes of their hosts and the environments in which they inhabit. Amblyospora connecticus Andreadis, 1988, a parasite of Ochlerotatus cantator (Coquillett) and Acanthocyclops vernalis (Fischer) is found in an unstable salt marsh environment that is subject to periodic flooding and drying. Both hosts have distinct non-overlapping generations. A. connecticus exhibits a well-defined seasonal transmission cycle that relies heavily on maternal-mediated transovarial transmission by female $O$. cantator during the summer, and horizontal transmission via the copepod host during the spring (copepod to mosquito) and fall (mosquito to copepod). Its survival strategies include: delayed virulence, low pathogenicity and high tissue specificity that allow for transstadial transmission of horizontally acquired infections and maximum spore production, reliance on living hosts throughout most of its life cycle with overwintering in the copepod, polymorphic development that is well synchronized with host physiology, and production and dissemination of infectious spores that are coincident with the seasonal occurrence of susceptible stages in each host. Hyalinocysta chapmani Hazard et Oldacre, 1975, a parasite of Culiseta melanura (Coquillett) and Orthocyclops modestus (Herrick) is found in a comparatively stable, subterranean habitat that is inundated with water throughout the year. Copepods are omnipresent and C. melanura has overlapping broods. H. chapmani is maintained in a continuous cycle of horizontal transmission between each host throughout the summer and fall but lacks a developmental sequence leading to transovarial transmission in the mosquito host. It relies on living hosts for most of its life cycle and overwinters in diapausing mosquito larvae. Transstadial transmission does not occur and there is no dimorphic development in the mosquito host. The spatial and temporal overlap of both mosquito and copepod hosts during the summer and fall affords abundant opportunity for continuous horizontal transmission and increases the likelihood that H. chapmani will find a target host, thus negating the need for a transovarial route. It is hypothesized that natural selection has favoured the production of meiospores in larval female mosquitoes rather than congenital transfer of infection to progeny via ovarian infection as a strategy for achieving greater transmission success. Analysis of the molecular phylogeny data suggest that (1) transovarial transmission and the developmental sequence leading to ovarian infection have been secondarily lost in $H$. chapmani, as they occur in all other closely related genera, (2) the ancestral state included complex life cycles involving transovarial transmission and an intermediate host, and (3) mosquito-parasitic microsporidia are adjusting their life cycles to accommodate host ecological conditions.
\end{abstract}

The polymorphic or heterosporous microsporidia that parasitize mosquitoes (Diptera: Culicidae) are a highly successful and widely distributed group that possess the most complex life cycles yet described for any microsporidia. These life cycles include aspects of asexual (merogony, schizogony and sporogony) and sexual (karyogamy, gametogenesis and plasmogamy) reproduction, the formation of multiple spore types, and both vertical (transovarial) and horizontal transmission. Many species require two host generations to complete their life cycle, and members of at least four genera, Amblyospora, Duboscqia, Hyalinocysta and Parathelohania require obligatory development in an intermediate copepod (Copepoda: Cyclopidae) host, the only microsporidia known to do so (Becnel and Andreadis 1999).

Despite their ubiquitous and widespread distribution among mosquitoes, detailed life history and epizootiological studies have been conducted on only a handful of species. These investigations have revealed a remarkable variety of unique and highly specialised adaptations particular to each parasite species that directly facilitate transmission and are intimately interwoven

This paper was presented at the NATO Advanced Research Workshop "Emergent Pathogens in the 21st Century: First United Workshop on Microsporidia from Invertebrate and Vertebrate Hosts", held in České Budějovice, Czech Republic, July 12-15, 2004. 
into the biological attributes of their hosts and the aquatic environments in which they inhabit. The objectives of this review are to critically examine the life cycle, transmission and survival strategies of two wellstudied species that both require intermediary development in a copepod host but employ very different survival strategies: (1) Amblyospora connecticus Andreadis, 1988 (Microsporidia: Amblyosporidae), a parasite of Ochlerotatus cantator (Coquillett) (Diptera: $\mathrm{Cu}-$ licidae) and Acanthocyclops vernalis (Fischer) (Copepoda: Cyclopidae), and (2) Hyalinocysta chapmani Hazard et Oldacre, 1975 (Microsporidia: Amblyosporidae), a parasite of Culiseta melanura (Coquillett) (Diptera: Culicidae) and Orthocyclops modestus (Herrick) (Copepoda: Cyclopidae). I further hope to demonstrate that changes in the complexity of the life cycles of these mosquito-parasitic species are not accidental but are adaptive and driven by natural selection which will favour those genotypes that lead to higher reproductive success and most importantly, transmission to a susceptible host. This will be achieved through a detailed review of the life cycle and epizootiology of each respective microsporidium and an examination of those factors that directly impact parasite reproduction, virulence, pathology, persistence, and overall transmission success.

\section{AMBLYOSPORA CONNECTICUS Andreadis, 1988}

\section{Host biology and habitat ecology}

Ochlerotatus (formerly Aedes) cantator, the "brown salt-marsh mosquito" inhabits the Atlantic coast of North America from Newfoundland to Virginia (Means 1979). It develops in temporary pools of brackish water (salinity range 3-8\%o) in the high marsh region of the intertidal zone where the predominant vegetation types include: spikegrass, Distichlis spicata, saltmeadow cordgrass, Spartina patens, common reedgrass, Phragmites australis, and jointed glasswort, Salicornia europaea. Ochlerotatus cantator is multivoltine and overwinters as a diapausing egg. In Connecticut, it may produce up to four distinct (non-overlapping) generations a year, each of which develops synchronously. Overwintering eggs of the first generation habitually hatch in early March. Larval development is slow (up to $8 \mathrm{wks}$ ) due to cool water temperatures, and adults do not usually emerge until mid-May. Subsequent broods develop more rapidly and arise throughout the summer and fall (June through November) whenever the marsh is flooded by extra-high tides and/or heavy rains.

Acanthocyclops vernalis is a common but highly variable copepod that inhabits almost all bodies of water in North America (Yeatman 1944). It has a life cycle typical of most cyclopoids that consists of an egg, six larval naupliar and six copepodid stages the last of which are the sexually dimorphic adults (Smith 2001). Although its life history is not entirely understood, it exhibits one to two generations a year in north- temperate regions and overwinters as a diapausing 4thor 5th-stage copepodid (Andrews 1953, Selgeby 1975). Laboratory studies (Cocker 1934) have also shown that this species becomes dormant at high temperatures (27$36^{\circ} \mathrm{C}$ ) and may form resistant cysts to survive dry periods (Smith 2001).

\section{Parasite life cycle}

Amblyospora connecticus has a complex life cycle that includes host sex-dependent polymorphic development, the production of three morphologically and functionally distinct spore types, maternal-mediated vertical (transovarial) transmission, and horizontal transmission via obligatory development in an intermediate copepod host (Andreadis 1983, 1985a, 1988a, b, 1990). The life cycle is illustrated in Fig. 1 and described below. Amblyospora connecticus is horizontally transmitted to larval $O$. cantator mosquitoes following oral ingestion of extracellular uninucleated (haploid) spores that are released into the water with the death of infected $A$. vernalis copepods. Spores germinate within the lumen of the larval gut and initially invade epithelial cells of the midgut and gastric caecum via injection of the sporoplasm through the evaginating polar tube. After a brief period of multiplication by binary fission (schizogony), the microsporidium spreads to muscle tissue and oenocytes where it undergoes a sexual phase of development involving gametogenesis and plasmogamy (cytoplasmic fusion) of uninucleated gametes, therein restoring itself to the diplokaryotic condition. Infected oenocytes become hypertrophied but there is no overt pathology associated with infection. Larval mosquito hosts develop normally and emerge as apparently healthy adults. Male mosquitoes are more susceptible and develop more progressive infections than larval female hosts. However, A. connecticus never sporulates in male hosts and paternal-mediated vertical transmission has not been demonstrated. Thus, the fate of these infections is unclear. In adult female hosts however, the microsporidium undergoes limited multiplication and sporulates when the female host acquires a blood meal. Sporulation coincides with the maturation of the ovaries and is stimulated by the secretion of host reproductive hormones, specifically 20-hydroxyecdysone (Lord and Hall 1983). This results in the formation of binucleated (diploid) spores that are typically found lying between the ovarioles and oocytes within the ovariole sheath. Spores germinate within 1 to 2 days, infect the ovaries via the nurse cells and are responsible for transovarial transmission of infection to the $\mathrm{F}_{1}$ generation.

Parasite development in larval progeny is dimorphic and dependent to some degree on the host sex. In approximately one-half of the female progeny, A. connecticus will infect the oenocytes and undergo a simple developmental sequence wherein it sustains limited multiplication by binary and multiple fission (merogony). These larvae show no adverse effects and develop normally to adulthood. When mated with healthy 


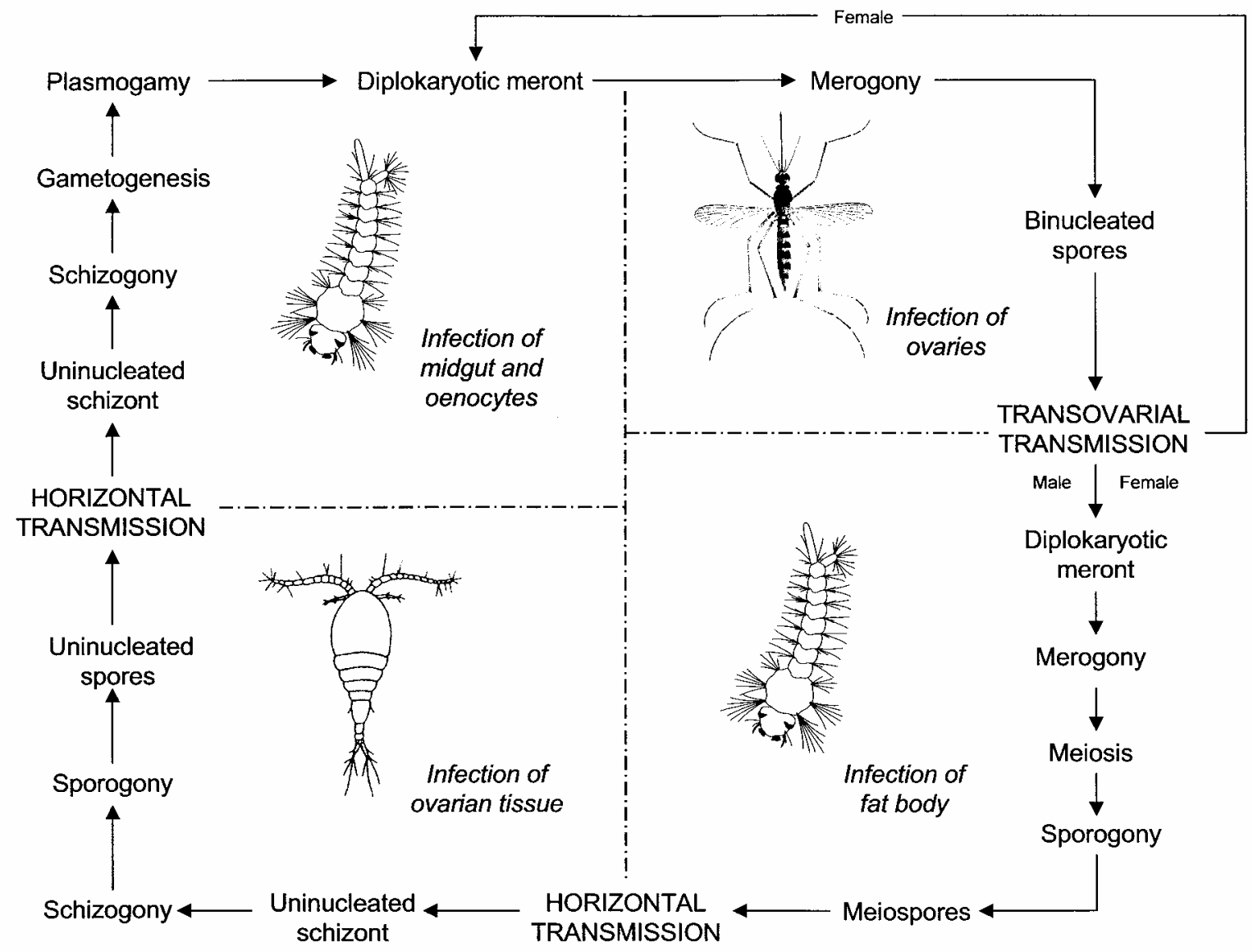

Fig. 1. Diagrammatic representation of the life cycle of Amblyospora connecticus in Ochlerotatus cantator and Acanthocyclops vernalis.

males and following a blood meal, they transovarially transmit infections as in the previous generation. In other female and usually all male progeny that hatch from infected eggs, the microsporidium invades fat body tissue and exhibits an entirely different developmental sequence. It initially undergoes a proliferative merogony during which infection spreads throughout the fat body of the larval host. Since no spores are formed at this time, it is presumed that diplokaryotic meronts are responsible for cell-to-cell transmission. Sporogony commences with the secretion of a sporophorous vesicle forming diplokaryotic sporonts that undergo meiosis and a prolonged sporulation sequence that results in the production of tens of thousands of haploid spores in groups of 8 that are commonly referred to as meiospores. Infections typically kill the larval host during the fourth stadium by destroying normal fat body function and depleting larvae of essential reserves. Meiospores produced in these mosquito larvae are orally infectious to copepodid and adult female $A$. vernalis. Following ingestion and subsequent spore germination, the microsporidium infects copepod ovarian tissue and undergoes repeated merogony followed by polysporoblastic sporogony and the formation of thousands of uninucleated haploid spores. This prevents egg development and ultimately kills the copepod, permitting the release of spores into the water where they can be eaten by mosquito larvae to complete the cycle. Amblyospora connecticus thereby persists by surviving in one of two living hosts throughout most of its life cycle.

\section{Parasite ecology and epizootiology}

It is apparent from examination of the life cycle and epizootiology of $A$. connecticus that this microsporidium has evolved a number of specific life history and transmission strategies that allow it to more fully exploit hosts that have distinct non-overlapping generations and inhabit an ephemeral aquatic habitat that is subject to episodic flooding and drying. These adaptations are intimately linked to the ecology of each host and are expressed annually in well-defined horizontal transmission events wherein the production and release of infectious spores are precisely timed with the seasonal development of each target host. These have been ascertained from epizootiological investigations conducted with natural field populations (Andreadis 1990), as revealed in Fig. 2. 
Amblyospora connecticus overwinters in late-stage copepodid $A$. vernalis. Moderately high (40-80\%) prevalence rates of infection are found in adult female and copepodid stages immediately after ice melt and these are comparable to the levels of infection observed in the copepod population in the preceding fall. An increase in the prevalence of infection is often observed in adult female copepods during the first few weeks. This is chiefly due to the molting of infected copepodids to adulthood. However, the possibility that some meiospores produced in mosquito larvae the previous fall, survive the winter, remain infectious, and are consumed by adult copepods at this time cannot be entirely dismissed. The re-emergence of infected $A$. vernalis in the spring is coincident with egg hatch of the mosquito $O$. cantator and horizontal transmission from copepod to mosquito takes place at this time. Larval mosquitoes acquire infection via oral ingestion of spores that are released into the pool with death of infected copepods. Both sexes are susceptible and transmission takes place throughout the 8-week period of larval development with overall prevalence rates approaching $60 \%$. Larval development is prolonged owing to cool water temperatures and this additionally facilitates transmission by increasing the "window of exposure" and potential encounters between infectious spores and the larval mosquito host. Infected larval mosquitoes develop benign infections that are largely confined to the oenocytes. Larvae mature normally and emerge as healthy adults. Female mosquitoes thus infected go on to vertically transmit the microsporidium to their progeny following blood feeding and ovarian infection.

Infected eggs are laid in the mud and vegetation throughout the remainder of the spring and summer months. However, hatch of eggs harbouring A. connecticus is inhibited as transovarially transmitted infections are only rarely detected in any summer broods of $O$. cantator larvae that arise when the habitat is inundated with water. These rarely produced individuals (mostly females) almost always develop a benign infection within the oenocytes that leads to ovarian infection and transovarial transmission once again. The apparent ability of $A$. connecticus to prevent the hatch of transovarially-infected mosquito eggs, perhaps by inhibiting embryonic development, during the summer months represents one of the more remarkable adaptations exhibited by this microsporidium as its target host $A$. vernalis aestivates and does not re-emerge until the fall. No horizontally transmitted infections of any kind are detected within the larval mosquito population at this time as well.

A synchronized hatch of transovarially infected mosquito eggs takes place in October and results in an epizootic of lethal meiospore infections in the larval mosquito population that approaches $90 \%$ and extends for nearly nine weeks. Infected mosquito larvae succumb to infection just before pupation and this results in the re- lease of a substantial inoculum of infectious meiospores into the water. This phenomenon represents an exceedingly important survival mechanism for $A$. connecticus as it coincides with the re-emergence of its target host A. vernalis from aestivation. This directly enhances horizontal transmission from mosquito to copepod by ensuring that the inoculum of meiospores will be at its maximum level when susceptible copepod hosts are plentiful. Horizontal transmission to $A$. vernalis is achieved via oral ingestion of meiospores and this results in moderately high prevalence rates of infection in the copepod population that continue to be detected up until the pool freezes in late December.

\section{Evolutionary strategies and adaptations for survival}

Amblyospora connecticus like all species of Amblyospora that have been investigated thus far, has evolved an indirect method of horizontal transmission that requires intermediary development in a copepod host. The adaptive significance of involving another living host in the life cycle is undoubtedly complex, and is probably driven by several factors that collectively increase the likelihood of producing viable parasite progeny and achieving greater transmission success. Assuming that the rate at which this or any microsporidium is acquired and disseminated horizontally within a host population is directly proportional to the number of encounters made between susceptible hosts and the spore inoculum (Anderson and May 1981, Dunn and Smith 2001), then a clear selective advantage can be seen in this interrelationship where the mosquito host, $O$. cantator, has distinct non-overlapping generations with uniform egg hatch and larval development. As a result very few if any mosquito larvae are present within the pool when mature meiospores are eventually liberated from fourth-instar larval cadavers in the fall. Copepods, on the other hand, are copiously abundant. The capacity to infect the copepod thus allows $A$. connecticus to maximize spore production in the fat body of older larger larvae and still ensures that these spores will be accessible to a susceptible target host. The same logic can be applied to the horizontal transmission events in the spring where the re-emergence of infected copepods, subsequent death and liberation of spores, precisely coincide with the hatch of susceptible mosquito larvae.

Development in an intermediate host further provides a mechanism for survival of this microsporidium in a living host throughout most of its life cycle rather than in the abiotic environment. This strategy eliminates the need to divert resources toward the production of a resistant free-living stage that is capable of surviving in a harsh unstable environment that is subject to periodic flooding and drying. Although, we have limited knowledge of the survival capabilities of microsporidia from aquatic hosts in the extra-corporeal environment, spores of $A$. connecticus are highly susceptible to desiccation and exhibit a significant loss in viability after storage in 


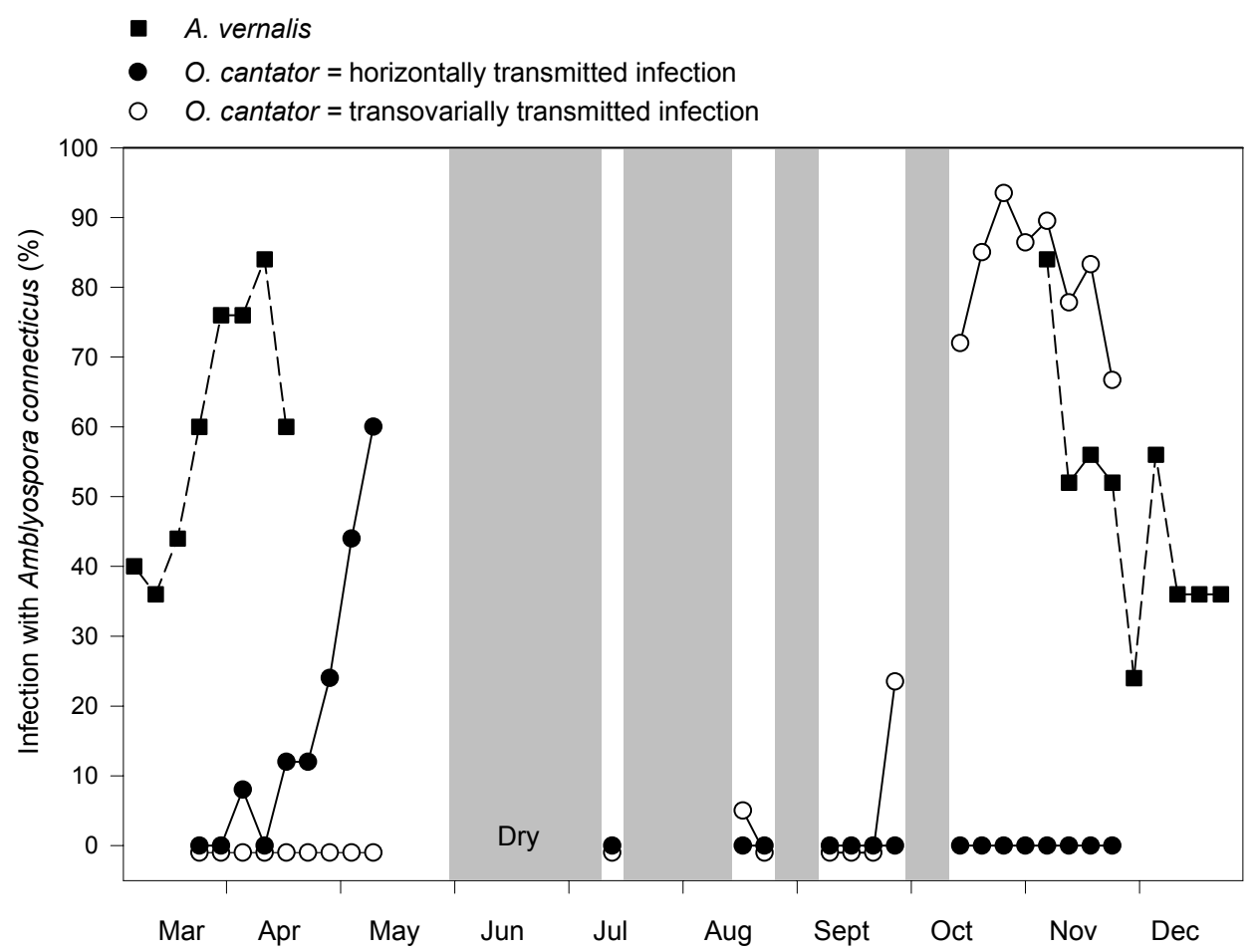

Fig. 2. Natural prevalence of horizontally and transovarially transmitted infections of Amblyospora connecticus in larval populations of Ochlerotatus cantator and adult female Acanthocyclops vernalis at a coastal saltmarsh habitat in Guilford, Connecticut, USA. Dry periods are indicated by the shading. Composite summary 1986-1988, adapted from Andreadis (1990).

water for 5 months at $4^{\circ} \mathrm{C}$ (Andreadis 1991), thus indicating that they are relatively short-lived. The ability to invade another host further enables $A$. connecticus to more fully exploit its biotic environment by increasing the opportunity for genetic variability and recombination. However, how and to what degree host genetic differences impact parasite heterogeneity has not been explored.

Transovarial transmission probably represents the single most important adaptation for survival that has evolved within $A$. connecticus. This phenomenon occurs in diverse branches of the Microsporidia (Dunn and Smith 2001) and can be found in all other species of Amblyospora that have been examined thus far (Becnel and Andreadis 1999). It provides a highly efficient and specialised mechanism wherein A. connecticus can be temporally maintained within the mosquito population when no susceptible stages of the intermediate copepod host are present. It further aids in the stabilisation of $A$. connecticus where mosquito and copepod densities oscillate from year to year and where both hosts possess distinct non-overlapping generations. The evolution of an entirely distinct developmental pathway that leads to the production of binucleated spores that function solely in ovarian infection within the female host mosquito, further indicate a strong selective pressure towards reliance on this method of transmission for dispersal and survival. This is in contrast to other species of vertically transmitted microsporidia such as Nosema or Vairimorpha that utilize the same spore type for both horizontal and vertical routes (Becnel and Andreadis 1999). These microsporidia generally rely more heavily on horizontal pathways and are typically less efficiently transmitted via the egg.

The degree to which maternal-mediated transovarial transmission contributes to continual maintenance of the parasite within a mosquito population varies widely among the numerous species of Amblyospora (Kellen et al. 1965, 1966, Andreadis and Hall 1979a, b, Lord et al. 1981, Sweeney et al. 1988, 1990). In A. connecticus, where roughly one-half of the infected female progeny develop benign infections and survive to transmit infections from one successive generation to the next, transovarial transmission can sustain the parasite for several generations in the absence of horizontal transmission. However, although transovarial transmission is continuous, some degree of horizontal transmission must eventually take place. This is because the maternal vertical transmission rate to female progeny is only $50 \%$ and there is no contribution from the male mosquito host (i.e. no paternal-mediated vertical transmission). This is generally true for all species of Amblyospora (Andreadis and Hall 1979b, Andreadis 1985b, Sweeney et al. 1988, 1989). Hurst (1991, 1993) and Sweeney et al. (1989) have hypothesized that in those aquatic habitats where copepods are abundant, the most effective long- 
term strategy may be for the microsporidium to increase meiospore production by producing such infections in female as well as male progeny even though there would be a corresponding decrease in the frequency of transovarial transmission. This occurs with $A$. connecticus in the fall when both sexes develop fatal meiospore infections as larvae. One might also anticipate that where copepods are sparse, natural selection would favour the evolution of benign oenocytic infections in females that would allow for continuous transfer of the microsporidium through female progeny. Sweeney et al. (1989) have shown that the proportion of a mosquito population that develop each type of infection (patent with meiospores and benign with transovarial transmission), can be influenced by genetic selection in laboratory experiments in as few as four generations. These studies collectively suggest that the expression of each of these two types of infection may be variable and in the case of $A$. connecticus, seasonally dependent. The degree to which such shifts in parasite development take place with species of Amblyospora that infect mosquito hosts that inhabit other environments is presently unknown. Transovarial transmission is also an important adaptation for long-range dispersal of $A$. connecticus to new habitats and for establishing new foci of infection in host populations. It provides an effective mechanism for introduction of the microsporidium into an aquatic environment where it can then be disseminated by horizontal means, provided an appropriate copepod host (i.e. A. vernalis) is present. Amblyospora connecticus thereby relies on the movements and ovipositional activities of its definitive host mosquito, which is highly mobile.

Although A. connecticus is pathogenic and eventually kills both hosts, it exhibits high tissue specificity and delayed virulence that is well synchronized with host development. These strategies enable it to more fully exploit each host stage and maximize both vertical and horizontal transmission efficiency. In adult female mosquitoes, there is no apparent pathology that might have a detrimental effect on host longevity, mating success, or fecundity, which would in turn negatively impact the transfer of the parasite to the next generation. Sporulation does not occur until a blood meal is taken and is controlled by host reproductive hormones (20hydroxyecdysone). This phenomenon is a highly significant adaptation that clearly serves to increase vertical transmission efficiency by ensuring that spore formation coincides with egg maturation. There is also little or no multiplication within the embryos of most transovarially-infected eggs. This is an equally significant strategy because it ensures that host mosquitoes do not succumb to infection while still within the egg and thus defeat the purpose for which transovarial transmission has evolved (Canning 1982). Development of $A$. connecticus in transovarially-infected larvae is restricted to fat body tissue where it produces large numbers of meiospores as larvae progress through three successive molts. The confinement to fat body tissue results in little or no disruption of metabolic processes that are essential for survival. Low virulence and high tissue specificity allow $A$. connecticus to maximize spore production in older larger larvae. This strategy does place a limitation on transmission however, as spore release into the environment and subsequent transmission can only take place with the disintegration of infected tissues following death of the host. This contrasts sharply with development within the alimentary tract where more rapid and continuous expulsion of infective inocula (spores) would be possible through all instar stages. Similar strategies of tissue selectivity and delayed mortality can be seen in the intermediate copepod host as well where infections are localised within female ovarian tissue. Egg production is inhibited, but the normal metabolic processes of the host are not seriously impeded. This allows the microsporidium to multiply and produce greater numbers of spores that will directly facilitate horizontal transmission to the mosquito host. No apparent pathology is observed in horizontally infected mosquito larvae where $A$. connecticus exhibits limited multiplication within epithelial cells of the gastric caeca, midgut and oenocytes. This strategy provides a clear mechanism for transstadial transmission during larval development to adulthood where the microsporidium can then be transovarially transmitted by female host. One enigmatic aspect in this phase of the life cycle is the apparent lack of function of horizontally transmitted infections in male mosquitoes. Laboratory (Andreadis 1988a) and field studies (Andreadis 1985b, 1990) have shown that male larvae are equally or even more susceptible to infection following the ingestion of spores. However, A. connecticus does not invade gonadal tissue and there is no evidence for venereal or paternalmediated vertical transmission. Therefore, males appear to be dead-end hosts for horizontally acquired infections. One can only assume that this lethal trait in male hosts is accordingly offset by the reproductive success in female hosts and highly efficient nature of transovarial transmission.

HYALINOCYSTA CHAPMANI Hazard et Oldacre, 1975

\section{Host biology and habitat ecology}

Culiseta melanura is a widespread mosquito that is distributed throughout the eastern and central United States (Darsie and Ward 1981). It is a multivoltine species that has two to three overlapping generations a year in the northeastern United States (Mahmood and Crans 1998) and is among the most dominant mosquitoes found in densely wooded freshwater swamps and sphagnum bogs in Connecticut (Andreadis et al. 1994). Females feed primarily on birds (Nasci and Edman 1981) and are active from June through October (Andreadis et al. 2001). Eggs are laid in water in permanent 


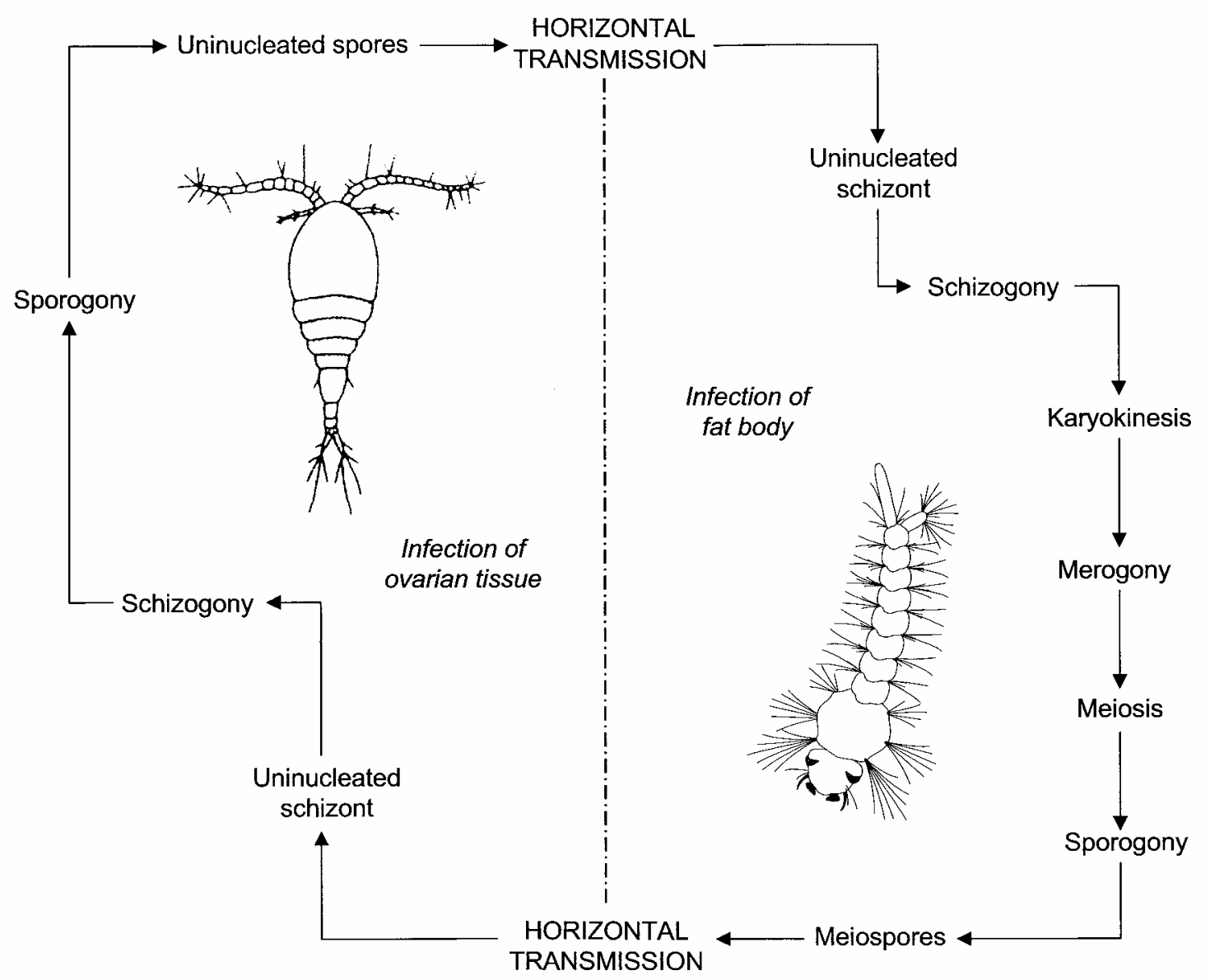

Fig. 3. Diagrammatic representation of the life cycle of Hyalinocysta chapmani in Culiseta melanura and Orthocyclops modestus.

subterranean habitats, and larvae develop in holes beneath mats of sphagnum and in deep shaded cavities around the roots of upturned trees (Pierson and Morris 1982) where water temperatures remain below $20^{\circ} \mathrm{C}$ most of the summer (Mahmood and Crans 1998). The habitat is comparatively stable and is generally inundated with water throughout the year. Larval development is exceptionally slow. Under controlled conditions egg hatch to adult emergence takes $8 \mathrm{mo}$ at $10^{\circ} \mathrm{C}, 3 \mathrm{mo}$ at $16^{\circ} \mathrm{C}$, and $1 \mathrm{mo}$ at $22^{\circ} \mathrm{C}$ (Mahmood and Crans 1998). The species is unusual in that it overwinters in the larval stage. The overwintering generation of larvae emerge as adults in the spring (June) and produce summer broods which are active from July through November. Eggs laid by the late-fall brood of adults produce larvae that make up the overwintering generation that emerge the following spring (Mahmood and Crans 1998).

Orthocyclops modestus is a small $(0.8-1.25 \mathrm{~mm})$ cyclopoid copepod species that is widely distributed throughout the United States and southern Canada (Yeatman 1959). It has been reported from a variety of aquatic habitats including small ephemeral vernal pools, shallow wells, moist soil impoundments in open areas of river floodplains, and permanent water beaver ponds (Duffy and LaBar 1994, Reid 2001). It is thought to survive dry periods in a dormant resting stage (Bruno et al. 2001) but is generally omnipresent and active throughout most of the year in subterranean sphagnum bog habitats in Connecticut (Andreadis 2002).

\section{Parasite life cycle}

Like $A$. connecticus, $H$. chapmani has a complex life cycle that includes polymorphism and horizontal transmission via a copepod host. However, H. chapmani is unique among all mosquito-parasitic microsporidia that have thus far been described in that it lacks a developmental sequence leading to a third spore type and transovarial transmission in the mosquito host (Andreadis and Vossbrinck 2002). The life cycle is illustrated in Fig. 3 and described below. Infections arise in C. melanura larvae following the oral ingestion of uninucleated spores previously formed in infected copepods. Spores germinate within the lumen of the midgut and directly invade fat body tissue where all development occurs. Males and females are equally susceptible and there is no sexually dependent dimorphic development. Hyalinocysta chapmani undergoes two phases of asexual re- 
production; an initial schizogony by binary division followed by karyokinesis (nuclear division) to create the diplokaryotic condition, and merogony by synchronous binary division. Sporogony and the accompanying host pathology are identical to that observed within $A$. connecticus. The onset is characterized by the simultaneous secretion of a sporophorous vesicle and meiotic division of the diplokaryon, which results in the formation of eight haploid meiospores enclosed within a sporophorous vesicle. Meiospores are released into the aquatic habitat by the tens of thousands with the death of infected larvae, which correspondingly succumb during the fourth stadium. Some infected individuals occasionally survive to adulthood due to a less intense infection, but there is no further parasite development that leads to either maternal- or paternal-mediated vertical transmission.

Hyalinocysta chapmani is horizontally transmitted to female $O$. modestus via oral ingestion of meiospores. With the exception of the size and shape of the spores and number of nuclei in the rosette-shaped sporogonial plasmodia, development of $H$. chapmani in $O$. modestus is virtually identical to that exhibited by $A$. connecticus in A. vernalis. Infections become established within ovarian tissue and all parasite development is haplophasic. Schizonts divide by binary division during an initial schizogonic cycle. This is followed by a sporogonic cycle in which sporonts secrete a sporophorous vesicle and undergo repeated nuclear division to form rosetteshaped sporogonial plasmodia with up to 18 nuclei. Cytoplasmic cleavage, sporogenesis and disintegration of the sporophorous vesicle ensue to form large numbers of membrane-free uninucleated spores. The ovaries become grossly distended, egg development is similarly inhibited and infections eventually become systemic. This results in death of the copepod and subsequent dispersal of spores into the aquatic environment where they are ingested by mosquito larvae to initiate a new cycle.

\section{Parasite ecology and epizootiology}

An examination of the natural epizootiology of $H$. chapmani (Andreadis 2002) reveals entirely different transmission dynamics than those observed with $A$. connecticus. These differences reflect the spatial and temporal overlap of both hosts and the comparatively stable environment in which they inhabit (Fig. 4). The subterranean site is inundated with water throughout the year, $O$. modestus copepods are generally omnipresent and $C$. melanura has overlapping broods. Hyalinocysta chapmani is enzootic and is maintained in a continuous cycle of horizontal transmission between each host that extends from April through November. The microsporidium overwinters in diapausing $C$. melanura larvae. Infected larvae are recovered in the early spring immediately after ice melt (March through May) and prevalence rates of infection ranging from $8 \%$ to $10 \%$ are typically observed up until pupation and adult emer- gence in late May. Horizontal transmission to copepod populations commences in May approximately six weeks after the initial detection of infected $C$. melanura larvae and is coincident with the liberation of infectious meiospores from fourth-instar cadavers. Horizontal transmission of $H$. chapmani from $O$. modestus copepods to $C$. melanura begins in June and is concurrent with the oviposition of the first generation of eggs of the summer population. Although some variation occurs from year to year, three successive cycles of horizontal transmission follow wherein developing mosquito larvae of the summer and fall generations acquire infections via oral ingestion of spores. These take place from mid-June to August, September to early October, and again in early November. Each of these transmission events is either preceded by or coincident with the detection of infected copepods in the habitat, thus inferring a continuous cycle of horizontal transmission between the two hosts. This interpretation is further corroborated from laboratory bioassays (Andreadis 2002) wherein oral transmission is consistently achieved in mosquito larvae that are reared in water and sediment samples taken from the site during the same time periods, thus confirming an infectious level of spore inoculum (from copepods) in the habitat. Peak infection rates, ranging from $48 \%$ to $60 \%$ are usually observed during the first cycle of larval development. These are coincident with the most sustained collections of infected copepods obtained during the year and highest levels of infection achieved in the laboratory transmission studies. Lower prevalence rates are observed with each ensuing host generation and transmission cycle, presumably due to a lower level of copepod spore inoculum. Each cycle represents a period of amplification of infection within the larval population as a result of continual oral ingestion of spores released from dying copepods. The steady increase in the prevalence of infection within each larval cohort is due to a slow rate of larval mosquito development in the cool subterranean habitat and absence of any parasite-induced mortality until just prior to pupation. The ensuing declines are attributed to the death of infected larvae during the fourth stadium and the recruitment of newly hatched larvae into the population. Infectious meiospores are released into the aquatic habitat with each cycle and are subsequently ingested by $O$. modestus copepods. Thus horizontal transmission between each host occurs continually throughout most of the year when larval mosquito host and copepods are present. Parasite development in mosquito larvae in November is retarded owing to cold water temperatures thus allowing for overwintering of $H$. chapmani in the diapausing larval host.

Evolutionary strategies and adaptations for survival

The absence of vertical transmission in the life cycle of $H$. chapmani and the sole reliance on horizontal transmission via an intermediate host are unique survival strategies not seen among other mosquito-parasitic 


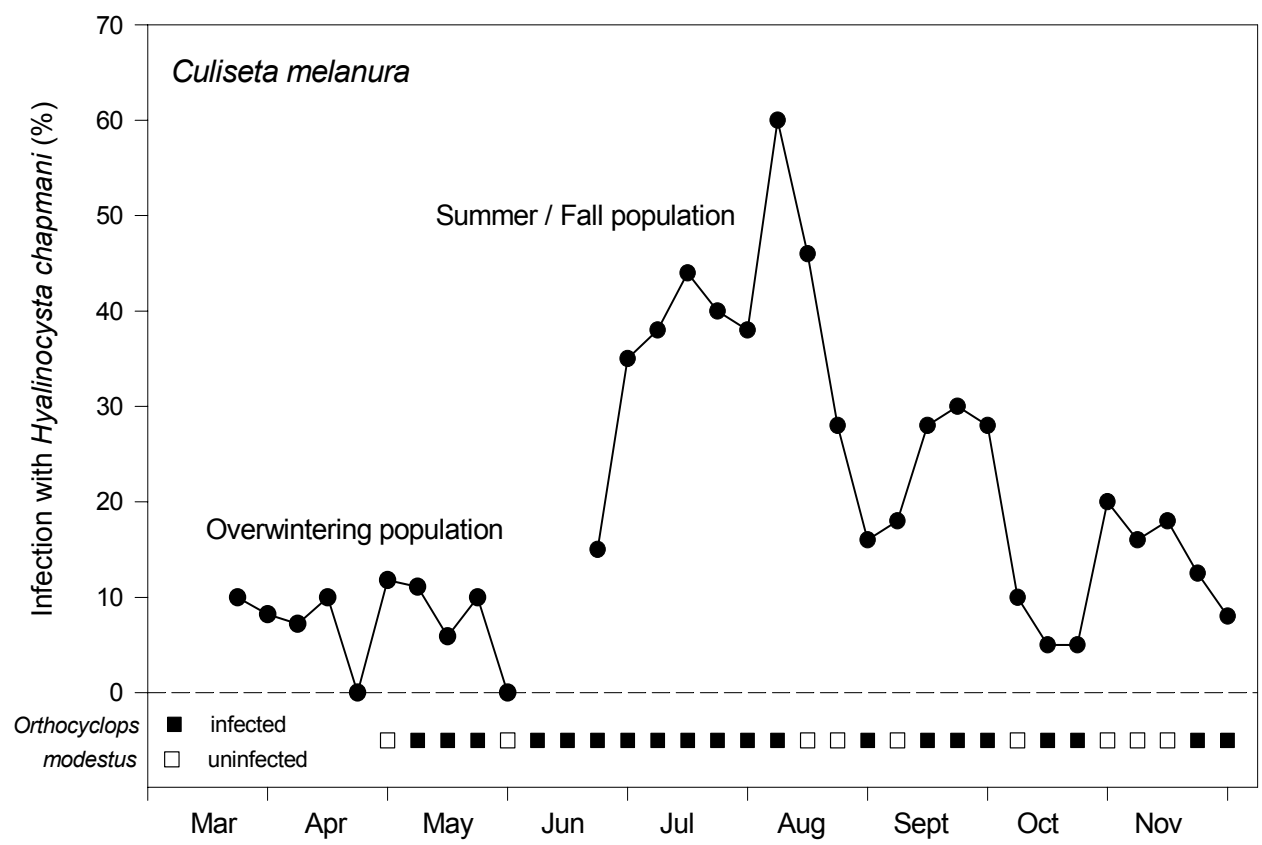

Fig. 4. Natural prevalence of horizontally transmitted infections of Hyalinocysta chapmani in larval populations of Culiseta melanura and adult female Orthocyclops modestus at a woodland subterranean habitat in Cornwall, Connecticut, USA. Composite summary 1995-1997, adapted from Andreadis (2002).

microsporidia. Vertical transmission is found in all other closely related genera (Amblyospora, Edhazardia, Culicosporella, Culicospora, and Parathelohania), and can be viewed as an important adaptation within these mosquito-parasitic groups. If the absence of transovarial transmission is adaptive rather than accidental, then this evolutionary strategy may be examined in the context of how it confers greater reproductive fitness and transmission success to $H$. chapmani. The life-cycle and epizootiological data suggest that this is a function of the biological attributes of the hosts and the environment which they occupy. The aquatic subterranean habitat that supports each host is inundated with water throughout the year and is very stable. Copepods are omnipresent and C. melanura has overlapping broods. Susceptible mosquito larvae in various stages of development can be found in intimate association with these copepods throughout much of the year. The spatial and temporal overlap of both hosts thus affords abundant opportunity for continuous horizontal transmission and increases the likelihood that $H$. chapmani will find a target host. Thus it appears that natural selection has favoured the production of meiospores in female host mosquitoes rather than congenital transfer of infection to progeny via ovarian infection as a more effective strategy for achieving greater transmission and reproductive success. This interpretation supports the aforementioned view (Sweeney et al. 1989, Hurst 1991, 1993) that where vertical transmission is poor or in this instance absent, and adequate copepod populations are available, the production of lethal meiospores in female as well as male mosquitoes can be a more advantageous strategy for parasite persistence. This type of hostparasite relationship in which both host sexes develop meiospore infections (albeit from transovarial transmission) has been noted in certain species of Amblyospora that parasitize multivoltine mosquitoes that similarly inhabit stable permanent bodies of water (Kellen et al. 1965, Anderson 1968, Sweeney et al. 1988, 1989). Additional life-cycle and epizootiological investigations, which examine the life-history strategies of other mosquito-parasitic microsporidia that infect hosts in a variety of habitats (ephemeral and permanent), are clearly needed to more fully appraise these theories. The absence of vertical transmission would further appear to be a major factor limiting long-range dispersal of $H$. chapmani to new habitats via infected female mosquitoes. This could result in more genetic heterogeneity between spatially isolated populations of $H$. chapmani as annual reintroduction and "mixing" of the microsporidium gene pool would be accordingly restricted. Conversely, one might also predict greater genetic similarity among populations of $A$. connecticus from different geographic locales within the flight range of adult female $O$. cantator. These are testable hypotheses that could be examined using highly polymorphic microsatellite DNA markers.

High tissue specificity and delayed pathogenicity are exhibited by $H$. chapmani in both the copepod and mosquito hosts. In C. melanura, all parasite development is localised in the fat body and there is little disruption of essential metabolic processes. Parasite reproduction and 


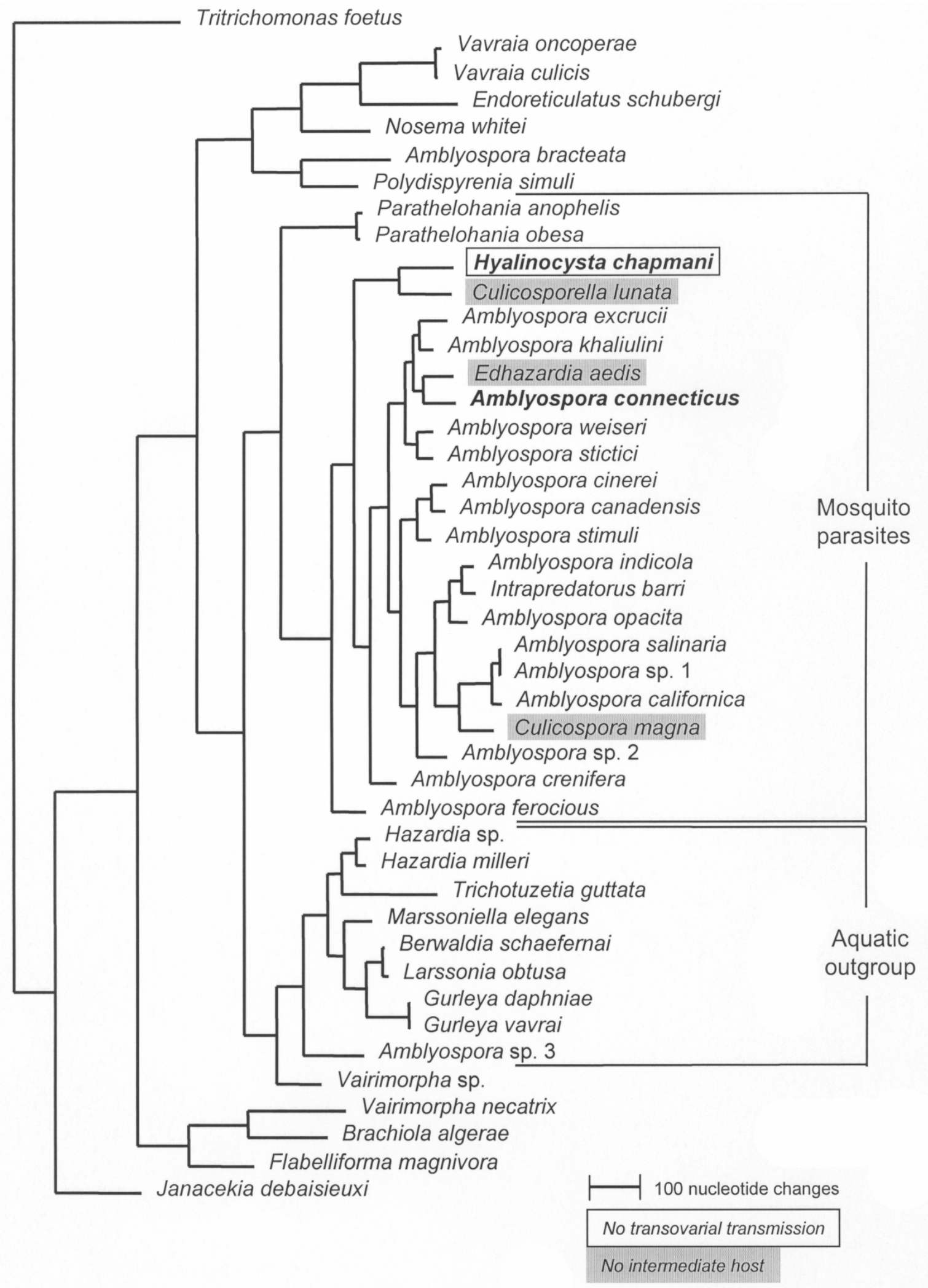

Fig. 5. Phylogenetic tree of microsporidia from mosquitoes, copepods and other aquatic crustaceans based on partial SSU rDNA using maximum parsimony analysis (single shortest tree of 5,762 steps), showing the position of Hyalinocysta chapmani, Amblyospora connecticus, and other mosquito-parasitic taxa that do not have an intermediate host. Adapted from Vossbrinck et al. (2004). 
multiplication proceed slowly as the host develops through four larval instars. This strategy, which may be more a function of the cool ambient water temperatures in which the host develops, nonetheless allows for maximum spore production. This increases the spore inoculum that is released into the aquatic habitat following death of the host and thus enhances the likelihood that copepods will encounter and ingest an infectious spore. A limiting factor with this strategy of course is that transmission cannot occur until death of the infected host, thus placing increased selective pressure on temporal as well as spatial synchronisation between the liberation of spores from infected cadavers and development of the target host. Parasite reproduction and multiplication in $O$. modestus proceed more rapidly in accordance with copepod development, but are equally restricted to nonessential tissues (i.e. ovaries and oviducts) therein allowing for increased spore production. These strategies of delayed pathogenicity and development in nonessential tissues appear to be universal among mosquito-parasitic microsporidia and their intermediate hosts regardless of whether infections are horizontally or vertically acquired.

Although no direct data are available on the longterm viability of free spores of $H$. chapmani in the external environment, the inability to infect $C$. melanura larvae in laboratory bioassays when larvae are exposed to water and sediment samples collected from the habitat in April and May, indicates that $H$. chapmani is unlikely to overwinter outside of the host. Thus, it appears that $H$. chapmani, like $A$. connecticus survives in one of two living hosts through much of its life cycle rather that in the external environment.

\section{MOLECULAR PHYLOGENY}

Examination of the phylogenetic relationships among microsporidian taxa from mosquitoes, copepods and other aquatic crustaceans provide additional insight into the origin and evolution of both the intermediate host and transovarial transmission. Fig. 7 is a maximum parsimony analysis tree of 43 microsporidian taxa based on sequences of the small subunit ribosomal RNA gene (Vossbrinck et al. 2004). The analysis contains: $16 \mathrm{Am}$ blyospora species from mosquitoes and copepods including A. connecticus; 3 monotypic genera from mosquitoes that fall within the Amblyospora clade (Culicospora, Edhazardia and Intrapredatorus); 4 sister taxa from mosquitoes (H. chapmani, Culicosporella lunata, Parathelohania anophelis and Parathelohania obesa); and 8 distantly related species from Anopheles mosquitoes (Hazardia milleri, Hazardia sp.), Cyclops spp.
(Trichotuzetia guttata, Marssoniella elegans), Daphnia spp. (Berwaldia schaefernai, Larssonia obtusa, Gurleya daphniae and Gurleya vavrai), and a blackfly (Amblyospora sp. 3) that form the "aquatic outgroup".

The analysis indicates that either the Parathelohania clade from Anopheles mosquitoes or the "aquatic outgroup" form the sister group to the Amblyospora/Hyalinocysta/Culicosporella taxa. This suggests that microsporidian parasites of anopheline and culicine mosquitoes evolved from parasites of crustaceans, and that parasitism of mosquitoes by all six mosquito-parasitic genera (Amblyospora, Culicosporella, Culicospora, Edhazardia, Intrapredatorus and Parathelohania) likely arose from a single event (Vossbrinck et al. 2004). Aside from the shape of the meiospore found in infected mosquito larvae, the life cycles, pathology and developmental morphologies of Parathelohania and Amblyospora are virtually identical; both genera have copepod intermediate hosts and are transovarially transmitted (Hazard and Weiser 1968, Avery and Undeen 1990). Culicospora magna and E. aedis also have morphologies and life cycles similar to the Amblyospora including transovarial transmission, but lack functional meiospores and the requirement for an intermediate copepod host (Becnel et al. 1987, 1989, Becnel 1994). Culicosporella lunata is transovarially transmitted but similarly lacks functional meiospores and an intermediate copepod host (Hazard et al. 1984, Becnel and Fukuda 1991). Thus, the absence of an intermediate host in the life cycles of these three species most likely reflects an ecological adaptation to the aquatic habitat of the larval host and is not a reflection of evolutionary relatedness. Analysis of the molecular phylogeny data further suggests that transovarial transmission and the developmental sequence leading to ovarian infection have been secondarily lost in $H$. chapmani, as they occur in all other closely related genera (Amblyospora, Edhazardia, Culicosporella and Culicospora) including the likely sister group Parathelohania. These observations collectively suggest that (1) mosquito-parasitic microsporidia are adjusting their life cycles to accommodate host ecological conditions, (2) the ancestral state included a complex life cycle involving transovarial transmission as well as an intermediate host, and (3) that parts of the life cycle can be gained and lost relatively rapidly over evolutionary time (Baker et al. 1997, 1998, Vossbrinck et al. 2004).

Acknowledgements. I thank Michael Thomas for assistance in preparation of the life-cycle figures and Dr. Charles Vossbrinck for providing the phylogenetic tree analysis. 


\section{REFERENCES}

ANDERSON J.F. 1968: Microsporidia parasitizing mosquitoes collected in Connecticut. J. Invertebr. Pathol. 11: 440-455.

ANDERSON R.M., MAY. R.M. 1981: The population dynamics of microparasites and their invertebrate hosts. Phil. Trans. R. Soc. London B, 291: 451-524.

ANDREADIS T.G. 1983: Life cycle and epizootiology of Amblyospora sp. (Microspora: Amblyosporidae) in the mosquito, Aedes cantator. J. Protozool. 30: 509-518.

ANDREADIS T.G. 1985a: Experimental transmission of a microsporidian pathogen from mosquitoes to an alternate copepod host. Proc. Natl. Acad. Sci. U.S.A. 82: 5574 5577.

ANDREADIS T.G. 1985b: Life cycle, epizootiology and horizontal transmission of Amblyospora sp. (Microspora: Amblyosporidae) in a univoltine mosquito, Aedes stimulans $\mathrm{J}$. Invertebr. Pathol. 46: 31-46.

ANDREADIS T.G. 1988a: Comparative susceptibility of the copepod, Acanthocyclops vernalis to a microsporidian parasite, Amblyospora connecticus from the mosquito, Aedes cantator. J. Invertebr. Pathol. 52: 73-77.

ANDREADIS T.G. 1988b: Amblyospora connecticus sp. nov. (Microsporida: Amblyosporidae): horizontal transmission studies in the mosquito, Aedes cantator and formal description. J. Invertebr. Pathol. 52: 90-101.

ANDREADIS T.G. 1990: Epizootiology of Amblyospora connecticus (Microsporida) in field populations of the saltmarsh mosquito, Aedes cantator, and the cyclopoid copepod, Acanthocyclops vernalis. J. Protozool. 37: 174182.

ANDREADIS T.G. 1991: Experimental observations on meiospore longevity in Amblyospora connecticus (Microsporida). J. Invertebr. Pathol. 58: 458-460.

ANDREADIS T.G. 2002: Epizootiology of Hyalinocysta chapmani (Microsporidia: Thelohaniidae) infections in field populations of Culiseta melanura (Diptera: Culicidae) and Orthocyclops modestus (Copepoda: Cyclopidae): a three-year investigation. J. Invertebr. Pathol. 81: 114121.

ANDREADIS T.G., ANDERSON J.F., VOSSBRINCK C.F. 2001: Mosquito surveillance for West Nile virus in Connecticut, 2000: isolation from Culex pipiens, Culex restuans, Culex salinarius and Culiseta melanura. Emerg. Infect. Dis. 7: 670-674.

ANDREADIS T.G., CAPOTOSTO P.M., SHOPE R.E., TIRRELL S.J. 1994: Mosquito and arbovirus surveillance in Connecticut 1991-1992. J. Am. Mosq. Control Assoc. 10: 556-564.

ANDREADIS T.G., HALL D.W. 1979a: Development, ultrastructure, and mode of transmission of Amblyospora sp. (Microspora) in the mosquito. J. Protozool. 26: 444-452.

ANDREADIS T.G., HALL D.W. 1979b: Significance of transovarial infections of Amblyospora sp. (Microspora: Thelohaniidae) in relation to parasite maintenance in the mosquito Culex salinarius. J. Invertebr. Pathol. 34: 152157.
ANDREADIS T.G., VOSSBRINCK C.R. 2002: Life cycle, ultrastructure and molecular phylogeny of Hyalinocysta chapmani (Microsporidia: Thelohaniidae) a parasite of Culiseta melanura (Diptera: Culicidae) and Orthocyclops modestus (Copepoda: Cyclopidae). J. Eukaryot. Microbiol. 49: 350-364.

ANDREWS T.F. 1953: Seasonal variation in relative abundance of Cyclops vernalis Fischer, Cyclops bicuspidatus Claus, and Mesocyclops leuckarti (Claus) in western Lake Erie, from July, 1946, to May, 1948. Ohio J. Sci. 53: 90 101.

AVERY S.W., UNDEEN A.H. 1990: Horizontal transmission of Parathelohania anophelis to the copepod, Microcyclops varicans, and the mosquito Anopheles quadrimaculatus. J. Invertebr. Pathol. 56: 98-105.

BAKER M.D., VOSSBRINCK C.R., BECNEL J.J., ANDREADIS T.G. 1998: Phylogeny of Amblyospora (Microsporidia: Amblyosporidae) and related genera based on small subunit ribosomal DNA data: a possible example of host parasite speciation. J. Invertebr. Pathol. 71: 199-206.

BAKER M.D., VOSSBRINCK C.R., BECNEL J.J., MADDOX J.V. 1997: Phylogenetic position of Amblyospora Hazard \& Oldacre (Microspora: Amblyosporidae) based on small subunit rRNA data and its implication for the evolution of the Microsporidia. J. Eukaryot. Microbiol. 44: 220-225.

BECNEL J.J. 1994: Life cycles and host-parasite relationships of microsporidia in culicine mosquitoes. Folia Parasitol. 41: 91-96.

BECNEL J.J., ANDREADIS T.G. 1999: Microsporidia in insects. In: M. Witter and L.M. Weiss (Eds.), The Microsporidia and Microsporidiosis. ASM Press, Washington, DC, pp. 447-501.

BECNEL J.J., FUKUDA T. 1991: Ultrastructure of Culicosporella lunata (Microsporida: Culicosporellidae fam. n.) in the mosquito Culex pilosus (Diptera: Culicidae) with new information on the developmental cycle. Eur. J. Protistol. 26: 319-329.

BECNEL J.J., HAZARD E.I., FUKUDA T., SPRAGUE V. 1987: Life cycle of Culicospora magna (Kudo, 1920) (Microsporida: Culicosporidae) in Culex restuans Theobald with special reference to sexuality. J. Protozool. 34: 313-322.

BECNEL J.J., SPRAGUE V., FUKUDA T., HAZARD E.I. 1989: Development of Edhazardia aedis (Kudo, 1930) n. g., n. comb. (Microsporida: Amblyosporidae) in the mosquito Aedes aegypti (L.) (Diptera: Culicidae). J. Protozool. 36: 119-130.

BRUNO M.C., LOFTUS W.F., REID J.W., PERRY S.A. 2001. Diapause in copepods (Crustacea) from ephemeral habitats with different hydroperiods in Everglades National Park (Florida, U.S.A.). Hydrobiologia 453/454: 295-308.

CANNING E.U. 1982: An evaluation of protozoal characteristics in relation to biological control of pests. Parasitology 84: 119-149. 
COCKER R.E. 1934: Reaction of some freshwater copepods to high temperatures. J. Elisha Mitchell Sci. Soc. 50: 143159.

DARSIE R.F. Jr, WARD R.A. 1981: Identification and geographic distribution of mosquitoes of North America, north of Mexico. Mosq. Syst. 1 (Suppl.): 1-313.

DUFFY W.G., LABAR D.J. 1994: Aquatic invertebrate production in southeastern USA wetland during winter and spring. Wetlands 14: 88-97.

DUNN A.M., SMITH J.E. 2001: Microsporidian life cycles and diversity between virulence and transmission. Microbes Infect. 3: 381-388.

HAZARD E.I., FUKUDA T., BECNEL J.J. 1984: Life cycle of Culicosporella lunata (Hazard \& Savage, 1970) Weiser, 1977 (Microspora) as revealed in the light microscope with a redescription of the genus and species. J. Protozool. 31: 385-391.

HAZARD E.I., WEISER J. 1968: Spores of Thelohania in adult female Anopheles: development and transovarial transmission, and redescriptions of $T$. legeri Hesse and $T$. obesa Kudo. J. Protozool. 15: 817-823.

HURST L.D. 1991: The incidences and evolution of cytoplasmic male killers. Proc. R. Soc. Lond. 244: 91-99.

HURST L.D. 1993: The incidences, mechanisms and evolution of cytoplasmic sex ratio distorters in animals. Biol. Rev. 68: 121-193.

KELLEN W.R., CHAPMAN H.C., CLARK T.B., LINDEGREN J.E. 1965: Host-parasite relationship of some Thelohania from mosquitoes (Nosematidae: Microsporidia). J. Invertebr. Pathol. 7: 161-166.

KELLEN W.R., CHAPMAN H.C., CLARK T.B., LINDEGREN J.E. 1966. Transovarian transmission of some Thelohania (Nosematidae: Microsporidia) in mosquitoes of California and Louisiana. J. Invertebr. Pathol. 8: 355359.

LORD J.C., HALL D.W. 1983: Sporulation of Amblyospora (Microspora) in female Culex salinarius: induction by 20 hydroxyecdysone. Parasitology 87: 377-383.

LORD J.C., HALL D.W., ELLIS E.A. 1981. Life cycle of a new species of Amblyospora (Microspora: Amblyosporidae) in the mosquito Aedes taeniorhynchus. J. Invertebr. Pathol. 37: 66-72.

MAHMOOD F., CRANS W.J. 1998: Effect of temperature on the development of Culiseta melanura (Diptera: Culicidae) and its impact on the amplification of eastern equine encephalomyelitis virus in birds. J. Med. Entomol. 35: 1007-1012.
MEANS R.G. 1979: Mosquitoes of New York. Part I. The Genus Aedes Meigen with Identification Keys to Genera of Culicidae. N.Y. State Mus. Bull. 430a, 221 pp.

NASCI R.S., EDMAN J.D. 1981: Blood-feeding patterns of Culiseta melanura (Diptera: Culicidae) and associated sylvan mosquitoes in southeastern Massachusetts. J. Med. Entomol. 118: 493-500.

PIERSON J.W., MORRIS C.D. 1982: Epizootiology of eastern equine encephalomyelitis virus in upstate New York, USA. IV. Distribution of Culiseta (Diptera: Culicidae) larvae in a freshwater swamp. J. Med. Entomol. 19: 423428.

REID J.W. 2001: Copepod crustaceans from the lower Oconaluftee River Valley, Great Smoky Mountains National Park. http: //www. npslandexchange. com/docs/ copepods.pdf

SELGEBY J.H. 1975: Life histories and abundance of crustacean zooplankton in the outlet of Lake Superior, 1971-72. J. Fish. Res. Board Can. 32: 461-470.

SMITH D.G. 2001: Pennak's Freshwater Invertebrates of the United States, Porifera to Crustacea. 4th Edition. John Wiley \& Sons, New York, 648 pp.

SWEENEY A.W., DOGGETT S.L., GULLICK G. 1989: Laboratory experiments on infection rates of Amblyospora dyxenoides (Microsporida: Amblyosporidae) in the mosquito Culex annulirostris. J. Invertebr. Pathol. 53: 85-92.

SWEENEY A.W., DOGGETT S.L., PIPER R.G. 1990: Life cycle of Amblyospora indicola (Microspora: Amblyosporidae), a parasite of the mosquito Culex sitiens and of Apocyclops sp. copepods. J. Invertebr. Pathol. 55: 428434.

SWEENEY A.W., GRAHAM M.F., HAZARD E.I. 1988: Life cycle of Amblyospora dyxenoides sp. nov. in the mosquito Culex annulirostris and the copepod Mesocyclops albicans. J. Invertebr. Pathol. 51: 46-57.

VOSSBRINCK C.R., ANDREADIS T.G., VAVRA J., BECNEL J.J. 2004: Molecular phylogeny and evolution of mosquito parasitic Microsporidia (Microsporidia: Amblyosporidae). J. Eukaryot. Microbiol. 51: 88-95.

YEATMAN H.C. 1944: American cyclopoid copepods of the viridis-vernalis group, (including a description of Cyclops carolinianus n. sp.). Am. Midl. Nat. 32: 1-90.

YEATMAN H.C. 1959: Cyclopida. In: W.T. Edmonson (Ed.), Fresh-Water Biology. John Wiley, New York, pp. 795815. 